\title{
O ROSTO DO AMOR
}

paulo de andrade

UFMG

\begin{abstract}
RESUMO
Sabemos que o rosto é um grande ícone da identidade, portanto o estabelecimento de seus traços corresponde, em maior ou menor grau, à configuração tanto de uma subjetividade quanto dos vínculos de pertencimento desse sujeito a uma cultura, uma comunidade. Se a literatura é um modo de cunhar - ou mesmo inventar - esse rosto, há, contudo, obras que, como a de Marguerite Duras, parecem trabalhar num movimento diverso, fazendo o rosto emergir como outro, impedindo a cristalização de sua identidade, atravessando-a constantemente com o estrangeiro, o desconhecimento, o amor à diferença como possibilidade de criação.
\end{abstract}

PALAVRAS-CHAVE

rosto, Marguerite Duras, escrita, amor.

Deixar o lugar conhecido, vivido - a paisagem, o rosto - pelo lugar desconhecido - o deserto, o novo rosto, a miragem? -

Edmond Jabès

$\mathrm{U}_{\mathrm{m}}$ retrato: uma mulher que olha, pousa seu olhar entre a serenidade do vazio e a delicadeza de uma determinação silenciosa, quase ignorada. Parece que conhecemos esse rosto de mulher, esse nome. Ele se estampa ao longo de toda uma obra, faz-se conjuntamente a ela. Sim, é Marguerite Duras, escritora. Mas a superfície da imagem, à primeira vista, lega-nos a dúvida: será uma artista francesa ou uma monja indiana? Cidadã francesa, nascida na Indochina, filha de um casal de professores que emigraram para a Ásia sob a influência da então política colonial, a pequena Marguerite tem por berço esse sul longínquo do Oriente, com sua terra maldita, seu calor infernal. Aí, nessas terras acometidas pelo Mar da China, viverá até o fim da adolescência, quando parte definitivamente para a França. Contudo, guardará em si essa infância de fim do mundo. Receberá no corpo a noite primeva da terra natal. Seu rosto terá os traços transformados, redesenhados, como se desse a ver aí, plantada sobre o império francês, imiscuída em seu coração mais fundo, uma doença anamita:

Mas na verdade os Donnadieu vivem mais próximos dos autóctones do que dos franceses. (...) Só brincam com crianças anamitas, falam a língua delas e, aliás, curiosamente, parecem pequenos mestiços. Raquíticos, vivos e asiáticos. Apesar dos esforços da senhora Donnadieu para marcar a diferença, eles são, antes de mais nada, moldados pelo mato, impregnados pelo país a ponto de serem fisicamente 
transfigurados. Afinal, de onde vem esse mimetismo anamita? Como podem os filhos de um perigurdino e de uma picarda terem a pele amarela e os olhos meio puxados? ${ }^{1}$

Esse rosto, tanto mais vietnamita quanto mais francês, está exposto a nosso olhar. Assim como a vida que ele carrega: inscrita e reescrita em sua obra, nos contornos da obra, Marguerite Duras não cessa de fazer exterior essa história que sulca a sua face com a intensidade de um estilete. Insistência que quase torna o trabalho biográfico um esforço inútil: dessa vida, essa história, estamos cansados de ouvi-la, em suas múltiplas versões, suas facetas cambiantes; ela mesma, Duras, contou-nos tudo o que há para se saber; esse rosto, esse nome, nós já o conhecemos. Entretanto, aqui e ali, de tanto olharmos, repetidamente e a cada vez de forma diversa, ele muda. Esse rosto que chama pelo Oriente, estrangeiro, sem pátria, parece prefigurar uma terra ainda sem lugar, a dinastia de um povo ainda sem nome, desconhecido de si mesmo.

Não vejo o rosto. Vejo a beleza flutuar, indecisa, à proximidade do rosto, mas não posso fazer com que nele se funda até tornar-se sua, única. Creio que os olhos fechados deveriam ser verdes. Mas paro nos olhos. E embora consiga retê-los muito tempo nos meus, eles não me dão o todo do rosto. $O$ rosto permanece desconhecido. ${ }^{2}$

Luz imóvel, iluminadora, para que possamos ver esse rosto: contudo, ele resiste, insiste em permanecer assim, desconhecido, tal como o Oriente evocado pelos traços incomuns desse rosto e transfigurado em território ausente de todos os mapas, uma vez que não está a serviço de nenhuma cultura, não forma o conjunto de "outros símbolos, uma outra metafísica, uma outra sabença”, que se oporia ao Ocidente. Esse Oriente não é, aí, uma "realidade" histórica, filosófica ou política: apenas "um reservatório de traços cuja articulação (...) permite-nos 'roçar' a idéia de um sistema simbólico inaudito, inteiramente desgarrado do nosso", como se nos apontasse "a possibilidade de uma diferença, de uma mutação, de uma revolução na propriedade dos sistemas simbólicos", ${ }^{3}$ da qual esse rosto é apenas a aproximação cuidadosa, com sua beleza flutuante e inacabada.

E o que pode nos dizer esse rosto, esse Oriente? Aproximemo-nos dele mesmo sem vê-lo de todo. Por vezes temos um rosto de criança, cuja delicadeza da pele não parece dissimular a malícia feminina que dele emana; outras vezes o rosto envelhecido, marcado em toda a sua superfície, como uma frágil porcelana que trincou em um ponto e foi expandindo sua fissura; outras vezes ainda é a mulher madura quem surge, com um ar elegante, certa sofisticação na pose, os óculos aludindo ao mundo dos livros, ao trabalho da escrita, ao intelecto. Esses rostos se repetem e se proliferam, exaustivamente, sobrepondose um ao outro, como máscaras que ocultam, cada uma, um fragmento da verdade que tem por nome essas cinco letras: DURAS.

Mas, talvez devido a esse Oriente que os assombra, da teatralidade eles não roubam o caráter representativo, a busca de uma identidade fundada na semelhança. Como um rosto teatral asiático - mascarado, pintado ou desenhado -, que não esconde o rosto do

\footnotetext{
${ }^{1}$ Lebelley. Marguerite Duras: uma vida por escrito, p. 4.

${ }^{2}$ Duras. O homem sentado no corredor, p. 11-2.

${ }^{3}$ BARTHEs. L'empire des signes, p. 7-8. As citações de textos em francês foram traduzidas pelo autor do artigo.
} 
ator, não o oculta como a um segredo, uma verdade subjacente à ficção, esses rostos, essas idades não encobrem nada. Ao contrário, essa suposta verdade é como que desfeita, diluída (no teatro, a base branca vem "apagar o rastro anterior dos traços", fazer do rosto um "tecido opaco", 4 sem textura, sem expressão, sem imagem). O rosto é "reduzido aos significantes elementares da escritura (o vazio da página e o oco de suas incisões [os olhos e a boca] ) ", 5 dispensando todo significado, toda expressividade. Portanto, não é um falso rosto que vem recobrir o original (ou um primeiro que se multiplicaria, se despedaçaria em muitos), mas, antes, a escavação de um rosto despido, lavado do nome; a aparição de um rosto sem cara; a imagem na sua condição de ausência; "a coisa por escrever". ${ }^{6}$ O que acaba por desvelar no rosto, em todo rosto, a potencialidade clandestina de fazer

com que os próprios traços de rostidade se subtraiam enfim à organização do rosto, não se deixem mais subsumir pelo rosto, sardas que ecoam no horizonte, cabelos levados pelo vento, olhos que atravessamos ao invés de nos vermos neles, ou ao invés de olhálos no morno face a face das subjetividades significantes. ${ }^{7}$

Assim, esse rosto público, que está à mostra em livros, jornais, revistas, programas de televisão, cartazes de filmes; esse rosto tão facilmente reconhecível, que se oferece incansavelmente ao reconhecimento, à leitura; esse rosto, de fato, não se fixa em nossas retinas, não podemos retê-lo, fundi-lo aos seus próprios traços; parece, de súbito, ter os olhos fechados, que poderiam ser verdes - ou azuis. Esse rosto infinitamente visto não nos é - como prevê-lo? - tão familiar, tão nítido, tão inteiro quanto queríamos: ele toma em seu curso comum uma direção imprevista:

Certo dia, já na minha velhice, um homem se aproximou de mim no saguão de um lugar público. Apresentou-se e disse: "Eu a conheço há muito, muito tempo. Todos dizem que era bela quando jovem, vim dizer-lhe que para mim é mais bela hoje do que em sua juventude, que eu gostava menos de seu rosto de moça do que desse de hoje, devastado."

Penso freqüentemente nessa imagem que só eu ainda vejo e sobre a qual jamais falei a alguém. Está sempre lá no mesmo silêncio, maravilhosa. É entre todas a que me faz gostar de mim, na qual me reconheço, a que me encanta.

Muito cedo na minha vida ficou tarde demais. Quando eu tinha dezoito anos, já era tarde demais. Entre dezoito e vinte e cinco meu rosto tomou uma direção imprevista. Aos dezoito anos envelheci. Não sei se é assim com todos, nunca perguntei. Creio que alguém já me falou dessa investida do tempo que nos acomete às vezes na primeira juventude, nos anos mais festejados da vida. Esse envelhecimento foi brutal. Eu o vi apossar-se dos meus traços um a um, alterar a relação que havia entre eles, aumentando o tamanho dos olhos, fazendo mais triste o olhar, mais definida a boca, marcando a testa com rugas profundas. Não tive medo e observei o envelhecimento do meu rosto com o interesse que teria dedicado a uma leitura. Sabia também que não estava enganada, que um dia ele ficaria mais lento, tomando seu curso normal. As pessoas

\footnotetext{
${ }^{4}$ BARTHEs. L'empire des signes, p. 119.

${ }^{5}$ BARTHEs. L'empire des signes, p. 121.

${ }^{6}$ Barthes. L'empire des signes, p. 120.

${ }^{7}$ Deleuze, Guattari. Mil platôs, v. 3, p. 36.
} 
que me haviam conhecido à época de minha viagem à França, quando eu tinha dezessete anos, ficaram impressionadas quando me viram dois anos mais tarde, com dezenove. Aquele rosto, novo, eu o conservei. Foi o meu rosto. Envelheceu também, é claro, mas relativamente menos do que devia. Tenho um rosto lacerado por rugas secas e profundas, sulcos na pele. Não é um rosto desfeito, como acontece com pessoas de traços delicados, o contorno é o mesmo, mas a matéria foi destruída. Tenho um rosto destruído. ${ }^{8}$

Estranha direção. Para onde nos levará? Para o Oriente perdido entre as águas de seus rios, as terras indochinesas sulcadas pelo Mekong e seus inumeráveis afluentes? Estranha passagem do tempo, que ora se antecipa, fazendo com que cedo seja tarde demais, imprimindo a marca de sua passagem antes do tempo, devastando, escavando brutalmente a planície da juventude; ora parece lento demais, quase imóvel, como se passasse com extrema doçura, envelhecendo o rosto menos do que deveria, ou mesmo como se jamais houvesse passado, conservando dele seu contorno inicial. Estranha beleza, percebida no apagamento de uma memória, na destruição de sua matéria, e que, contudo, não é anulação da forma, mas, antes, a forma da anulação, imagem silenciosa que encanta: como se o rosto acolhesse a morte - a passagem da vida -, servindo-lhe de suporte material; como se o rosto se fizesse dessa beleza da morte - ausência entalhada na pele, retorno aos mínimos traços, ao puro contorno, desvelamento do fundo vazio. Não um rosto desfeito, mas escrito, destruído, reduzido ao traço dessa destruição, que é a possibilidade última de todo recomeço, pois "só há traço no deserto, voz senão no deserto". 9

Então que rosto é esse, refratário, que se reconhece na maravilha de seu esquecimento, de sua inacessibilidade, que assiste à sua própria morte com a avidez de um leitor, que embaralha o tempo? Aqui, talvez, seja necessário notarmos que "o rosto envelhecido de Duras está conectado com o rosto invisível dos seus quinze anos, sendo o gozo o elemento insubstituível dessa conexão". ${ }^{10}$ Por esse rosto da primeira juventude, invisível como "uma página em branco, convite à escritura", ${ }^{11}$ passam a velhice, o álcool, os amantes, os livros, os filmes. Conectados, todos eles, pelos traços premonitórios desse terceiro rosto, impessoal, do gozo:

Aos quinze anos eu tinha o rosto do gozo e não conhecia o gozo. Os traços do gozo eram muito acentuados. Até minha mãe devia vê-los. Meus irmãos os viam. Tudo começou assim em minha vida, com esse rosto visionário, extenuado, as olheiras antecipando-se ao tempo, à experiência. ${ }^{12}$

Aquilo que se antecipa à experiência (da vida?), nesse rosto não-todo do gozo, ${ }^{13}$ só é dado, curiosamente, por meio da própria experiência. Qual? A do gozo? Se esse rosto visionário é, de certa forma, aquele que, nos livros, antecipa-se à massa gráfica da escrita, ou seja, se "esse rosto do gozo é a folha de rosto dos livros de Marguerite Duras", ${ }^{14}$

\footnotetext{
${ }_{8}^{8}$ Duras. O amante, p. 7-8.

${ }^{9}$ Jabès. Il n'y a de trace que dans le désert, p. 168.

${ }^{10}$ Mourão. Um rosto-palavra, p. 5.

${ }^{11}$ Mourão. Um rosto-palavra, p. 3-4.

${ }^{12}$ Duras. O amante, p. 13.

${ }^{13}$ Cf. Lacan. Deus e o gozo d'A Mulher.

${ }^{14}$ MourÃo. Um rosto-palavra, p. 5.
} 
antecipando-se também à leitura, talvez pudéssemos arriscar a dizer que a experiência que nos possibilita a antevisão desse rosto de gozo é a experiência literária - uma vez que é ela a destruição de todo rosto, onde reina a fascinação do neutro e do impessoal:

Escrever é dispor a linguagem sob o fascínio e, por ela, em ela, permanecer em contato com o meio absoluto, onde a coisa se torna imagem, onde a imagem, de alusão a uma figura se converte em alusão ao que é sem figura e, de forma desenhada sobre a ausência torna-se a presença informe dessa ausência, a abertura opaca e vazia sobre o que é quando não há mais ninguém, quando ainda não há ninguém. ${ }^{15}$

É com a obra, suportado por ela, que esse rosto emerge. Rosto de ninguém, de um alguém indeterminado, estrangeiro, e que, para Duras, tem sempre a tez branca dos amantes, evocada com mínimos traços: olhos azuis cabelos negros - assim escritos num só sintagma, sem a separação da vírgula que aí imprimiria um caráter meramente descritivo. Dessa forma, parece restar do instantâneo da linguagem justamente o inapreensível: olhos-azuiscabelos-negros - como se o negro dos cabelos fosse já um prolongamento do azul terrível e descentrado dos olhos, capaz de contaminar todo o rosto, arrastando-o para os buracos dos olhos, fazendo dele um imenso buraco azul, "como se o azul inteiro olhasse". ${ }^{16}$

Nesse livro, na escrita de Duras, um estrangeiro atravessará com seu rosto os outros personagens: um homem que não gosta de mulheres, uma mulher que gosta de homens ambos apaixonados pela lembrança, pela passagem fugaz desse rosto anônimo, porque "de fato o amor pode chegar assim, ao se ouvir dizer de um desconhecido como eram seus olhos". ${ }^{17}$ Esse homem e essa mulher, arrebatados por uma "união branca e desesperada", encontram-se noite após noite, num quarto fechado, para chorarem o rosto perdido do amor, esse rosto que é o de todos eles, de olhos azuis cabelos negros:

Ela se despe. Deita-se em seu lugar, sob a luz. Tem um olhar esquivo que chora sem saber, como o dele. Ele acha que se parecem. Diz a ela. Ela também acha, como ele, que têm a mesma altura, olhos do mesmo tom de azul, e cabelos pretos. Sorriem um para o outro. Ela diz: E, no olhar, a tristeza de uma paisagem noturna. ${ }^{18}$

A semelhança não é, contudo, planificada na mesma tristeza da paisagem noturna que carregam no olhar. Não se trata de um rosto uniforme, mas de um rosto indiscernível, que resiste em sua condição estrangeira, como um ponto de ignorância, de nãoconhecimento, reiterado a cada momento pelo gesto da mulher de cobrir seu rosto com a seda negra - véu lutuoso que carpe o rosto morto do amor.

- Quem é ele?

- Não sei. Nunca soube.

- E por que seria estrangeiro?

Ele não responde. Ela chora, sorri através das lágrimas.

- Para que vá embora para sempre?

- Provavelmente. ${ }^{19}$

\footnotetext{
${ }_{15}$ Blanchot. O espaço literário, p. 24.

${ }^{16}$ Duras. Olhos azuis cabelos negros, p. 15.

${ }^{17}$ Duras. Olhos azuis cabelos negros, p. 22.

${ }^{18}$ Duras. Olhos azuis cabelos negros, p. 34.

${ }^{19}$ Duras. Olhos azuis cabelos negros, p. 69.
} 
Incessantemente indo embora para sempre, o rosto do amor é procurado vislumbrado - na relação impossível entre o homem e a mulher, nus, fechados num mesmo quarto, entre lençóis brancos, rodeados pelo mar e pelos caminhantes noturnos da praia, que buscam sexo anônimo atrás dos rochedos. Incessantemente indo embora para sempre, o rosto do amor é procurado - vislumbrado - na relação impossível entre ele e a escritura, uma vez que "esse amor situa-se na impossibilidade de ser escrito. É um amor que ainda não foi atingido pela escritura". ${ }^{20}$ Por isso, sendo o livro "a história de duas pessoas que se amam" e estando elas cercadas pelas circunstâncias do enlace amoroso, "nada fazem, não fazem amor, esperam no escuro". ${ }^{21}$ O que esperam, contudo? O que fazem então para atravessar essa impossibilidade da escrita, do amor, do conhecimento de seu rosto?

Confundo-me àquelas pessoas e o que faço é contar uma história impossível como contaria uma história possível entre uma mulher e um homossexual, ao passo que o que desejo contar é uma história de amor que é sempre possível, mesmo quando se apresenta como impossível aos olhos das pessoas que estão longe da escritura - visto que a escritura não se preocupa com esse gênero do possível ou não da história. ${ }^{22}$

Fugindo da dicotomia do possível ou não da história - visto que a literatura é justamente o alcance desse ponto de pura potência da linguagem, por meio da linguagem, em que ela se faz um terceiro termo que só acolhe a possibilidade atravessada pela impossibilidade,$-^{23}$ esse amor quem sabe possa escrever-se ao abandonar a história, admitindo que "não houve história de amor entre as pessoas, e sim amor". ${ }^{24}$ Talvez o que o rosto cego do amor venha revelar não seja tanto o seu próprio rosto, mas um outro, branco, cuja brancura não é referência nem a um traço originário (aludindo a um rosto personificado, supostamente o do autor, que se confunde à escrita, aos personagens), nem étnico (signo irremediado de uma cultura, de um povo provável, "que há"). Antes, se esse branco retoma a materialidade da pele, é para arrastá-los - autor e povo - em direção ao seu desaparecimento:

Ele diz que começa a esquecer os olhos do jovem estrangeiro de olhos azuis cabelos negros. Ao despertar, às vezes até duvida que a história tenha existido. Como esse rosto que ela procurava sem saber, para ele o do jovem estrangeiro deve encobrir um outro, mas que ainda está por vir. Diz que o rosto cego de que ainda se lembra agora lhe parece hostil, brutal. ${ }^{25}$

O rosto só se faz promessa, fabulação de um novo rosto - aquele de um "povo que falta (que sempre falta)" - ${ }^{26}$ porque se subtrai ao rosto, à lembrança do rosto. Porque os sulcos no rosto não são apenas da experiência da vida, mas também "da desproporção das palavras, de sua pobreza, diante da enormidade da dor”. ${ }^{27}$ E, então, escreve-se. Faz-se, sem

\footnotetext{
${ }^{20}$ Duras. A vida material, p. 77.

${ }^{21}$ Duras. A vida material, p. 77.

${ }^{22}$ Duras. A vida material, p. 80.

${ }^{23}$ Cf. ANDrAde. O cinema sem imagens, p. 112.

${ }^{24}$ Duras. A vida material, p. 80.

${ }^{25}$ Duras. Olhos azuis cabelos negros, p. 65.

${ }^{26}$ Guimarães. O rosto do outro, p. 82.

${ }^{27}$ Duras. Olhos azuis cabelos negros, p. 114.
} 
saber, o amor. Busca-se, às cegas, o seu por vir, a sua miragem. Inventa-se esse traço branco, esse rosto imemorial e imaterial de um grito lançado há trinta mil anos em imagens sobre a pedra. Grito remoto, além e aquém do próprio homem. Grito escrito sobre o corpo morto desse amor, dessa morte de sua morte, de seu nome inominável.

Escrever não seria senão uma maneira de morrer das palavras de sua morte e o traço nada menos que a aclaração progressiva de uma sombra, ah brancura última.

Sob essa brancura, nós jazemos.

Sob esse imaterial rosto branco. ${ }^{28}$

\section{A}

\section{A B STRACT}

The face is one of the major icons of identity; therefore, the establishment of its distinctive traits corresponds to the configuration of subjectivity and of the ties connecting the subject to a culture or community. Though literature constitutes one of the means to coin-or to invent-this face, some writings, like Duras's, seem to follow a different strategy; as a result, the face emerges as an Other, which prevents the crystallization of its identity by creating a space for the emergence of the stranger, the unknown, the love for difference as a possibility of creation.

\section{KEY WORDS}

face, Marguerite Duras, writing, love.

\section{REFERÊNCIAS BIBLIOGRÁFICAS}

ANDRADE, paulo de. O cinema sem imagens. Aletria, Revista de Estudos de Literatura, Belo Horizonte, FALE/PÓS-LIT/CEL, n. 8, dez. 2001. p. 109-15. (Cinema \& Literatura)

Bamberger, Hélène et al. Marguerite Duras. Portraits d'auteurs. Paris: Marval, 1997.

Barthes, Roland. L'empire des signes. Paris: Flammarion, 1970. p. 7-10: Là-bas; p. 119-26:

Le visage écrit.

Blanchot, Maurice. O espaço literário. Trad. Álvaro Cabral. Rio de Janeiro: Rocco, 1987.

Deleuze, Gilles, Guattari, Félix. Mil platôs: capitalismo e esquizofrenia. Trad. Ana Lúcia de Oliveira et al. Rio de Janeiro: Ed. 34, 1996. v. 3. Cap. 7: Ano Zero - Rostidade, p. 31-61.

Duras, Marguerite. O amante. 13. ed. Trad. Aulyde Soares Rodrigues. Rio de Janeiro: Nova Fronteira, 1986.

Duras, Marguerite. O homem sentado no corredor. Trad. Sieni Plastino. Rio de Janeiro: Record, 1987.

Duras, Marguerite. Olhos azuis cabelos negros. 2. ed. Trad. Vera Adami. Rio de Janeiro: Nova Fronteira, 1993.

${ }^{28}$ JABÈs. Il n'y a de trace que dans le désert, p. 175. 
Duras, Marguerite. A vida material. Trad. Heloísa Jahan. Rio de Janeiro: Globo, 1989. p. 77-81: O livro.

Guimarães, César. O rosto do outro: ficção e fabulação no cinema segundo Deleuze. In: Lins, Daniel (Org.). Nietzsche e Deleuze: pensamento nômade. Rio de Janeiro: Relume Dumará, 2001. p. 81-93. (Col. Outros Diálogos, 6)

JABÈs, Edmond. Il n'y a de trace que dans le désert. In: Les livres des marges. Paris: Fata Morgana, 1987. p. 168-75.

LaCAN, Jacques. Deus e o gozo d'A Mulher. In: O seminário. Livro 20: mais, ainda. 2. ed. Trad. M.D. Magno. Rio de Janeiro: Jorge Zahar, 1985. p. 87-104.

Lebelley, Frédérique. Marguerite Duras: uma vida por escrito. Trad. Uéliton de Oliveira e Vilma de Katinszky. São Paulo: Página Aberta, 1994.

Mourão, Cleonice Paes Barreto. Um rosto-palavra: considerações sobre a escrita da memória em Marguerite Duras. (Texto inédito). 